\title{
Culturally-sensitive learning practices
}

\author{
Dr. Lesley S. J. Farmer \\ California State University Long Beach, 1250 Bellflower Blvd., Long Beach CA 90840 USA Email lfarmer@csulb.edu
}

\begin{abstract}
In today's global world, to provide meaningful education, teacher-librarians and their students need to become culturally competent: open to learning about other cultures and sharing one's own culture, able to change personal perspectives, and able to communicate effectively across cultures. Hofstede's model of cultural dimensions provides a framework for examining culturally-sensitive library implications. Specific strategies are suggested to address language barriers, student-teacher relations, choosing resources, learning activities, technical issues, and assessment.
\end{abstract}

\section{Introduction}

Globalisation impacts people's lives - and the preparation for those life choices. People are more likely to migrate so that schools have become more diverse. Concurrently, learners are seeking distance education delivery options in order to get the training needed from experts who may reside continents away. Particularly as Western educational philosophies do not reflect the preponderance of educational approaches worldwide, it behoves teacher-librarians to address cultural nuances, particularly in instruction.

\section{Background}

Culture may be defined as "the customary beliefs, social forms, and material traits of a racial, religious, or social group" and "the set of shared attitudes, values, goals, and practices that characterizes an institution or organization" (Webster's Dictionary). In education, cultural issues apply to the learner, the instructor, the intended learning environment, and the content of learning itself.

Hofstede's 1980 model of cultural dimensions and Biggs' 3P model of teaching and learning provide useful frameworks for examining culturally-sensitive library instruction implications (noted in italics).

- Power distance. What is the degree of equality between people? How equitable is the power distribution as defined from low-status people? In low-power societies, status is less important. Power distance impacts teacher-student relations.

- Individualism vs. collectivism. People in individualistic societies tend to belong to several groups, each of which is loosely-knit, while collectivist societies tend to have a few, well-defined groups who are highly loyal. In-group refers to a collective in which members are highly interdependent and have a sense of common fate; groups to which they do not belong are out-groups. Learners and teachers have preconceived attitudes about individual vs. cooperative efforts.

- Masculinity. To what degree are genders differentiated? Are traditional gendered roles supported in terms of achievement, control and power? How are women valued relative to men? In instruction, males might be more competitive or need more praise.

- Uncertainty avoidance. How tolerant is society of uncertainty and ambiguity? Are different options acceptable or are strict rules the norm? How structured should learning activities be? Does assessment ask for one right answer or does it encourage new answers? Do learning activities focus on accuracy or on different perspectives?

More specifically, different cultures tend to reinforce different learning styles. For example, collective societies tend to reinforce field dependent and non-linear learning. Instructors need to start a unit by giving the big picture, and they provide such learners with more guidance along the way (Chen \& Macredie, 2002).

The impact of culture may be analysed using Biggs' 1978 3P model of teaching and learning. Presage deals with experiences before learning takes place (i.e. learning characteristics, prior knowledge and experience), process occurs during learning (i.e. learning conditions, activities), and products focuses on the outcomes of

(C) 2010 IASL, SLAQ and therein by the authors. Diversity Challenge Resilience: School Libraries in Action Proceedings of the $12^{\text {th }}$ Biennial School Library Association of Queensland, the $39^{\text {th }}$ International Association of School Librarianship Annual Conference incorporating the $14^{\text {th }}$ International Forum on Research in School Librarianship, Brisbane QLD Australia, 27 September - 1 October 2010 . 
learning (e.g. assessments, application, context). Thus, learner experiences are interdependent with situational elements such as teaching factors (style, institutional procedures, assessment) and the learning environment (e.g. learning activities, social climate). Biggs also differentiates surface approaches to learning (i.e. reproducing information), deep approaches (thorough understanding), and achievement orientation (i.e. focus on grades). Biggs, Kember, \& Leung (2001) emphasise the importance of identifying which factors are universal and which are culturally-defined. Most significant are those practices that are imposed as if universal (e.g. outlining a report) that actually reflect specific cultural norms (e.g. North American); learners outside that teacher-centric culture may feel discounted or under-prepared.

Examination of the learner specifically leads to several contributing cultural factors that can impact teaching effectiveness:

- Language (idioms): native/primary language skills of reading and writing; the quality and quantity of second language experience and skill; formal vs. informal language usage; vocabulary and idiomatic knowledge

- Educational philosophy and experiences: role of education; curriculum and instruction practices; student behaviour norms (which might differ from the institution's expectations); learner-specific experiences

- Gender issues: sex-linked educational, career, and workplace expectations/norms that are culturally defined

- Age-linked cultural norms: generation-specific roles and expectations; familial roles and norms; roles and expectations impacted by global/social realities (e.g. digital natives)

- Knowledge of content: transmission of information patterns (e.g. family, academic counselling, libraries); cultural expectations and norms relative to specific disciplines; community needs and practices (e.g. local agricultural economy vs. globalised knowledge economy) (McMahon \& Bruce, 2002).

In an e-learning environment, technology significantly impacts student learning, and also is subject to cultural influence. For instance, learners might have different degrees of access due to cultural attitudes about technology, socially-constructed gender role expectations, and socio-economic values. World experience and knowledge impacts learners' ability to locate and evaluate online information. Even social attitudes about language acquisition and attitudes about English can impact online use.

As they work in cross-cultural settings, or at the very least work with learners from different cultures, teacher-librarians should strive for cultural competence. Kalyanpur and Harry (1999) list several benchmarks that note progress in this endeavour.

1. Cultural knowledge: one because familiar with cultural characteristics, history, behaviours and values of people of another cultural group.

2. Cultural awareness: understanding of another culture, changing attitudes about culture, and open flexibility in relating to people of another culture

3. Cultural sensitivity: realisation that cultural similarities and differences exist, without assigning relative value to those differences.

4. Cultural competence: congruent set of behaviours, attitudes and policies to enable one to work effectively in cross-cultural situation.

5. Cultural proficiency: a way of being that enables people to interact with others who are different from them.

\section{Connecting instruction to the larger environment}

Regardless of content, the student population is increasingly diversified in cultural background and experience. All too often, cultural sensitivity is overlooked when designing curriculum and delivery. Not only should teacher-librarians be aware of the impact of culture in their instruction, but they should leverage those cultural differences to provide a richer educational experience. 
Teacher-librarian instructors of diverse students need to help those learners navigate within the educational or home culture successfully. These skills might include learning social expectations and norms, identifying the cultural assumptions being made about presented (and missing) content, and communicating in socially acceptable ways (e.g. avoiding jargon, understanding social space). Furthermore, educational practice itself reflects culturally-defined philosophies. For example, a belief in the professor as the all-wise transmitter of knowledge opposes the idea of the instructor as a learning environment co-constructed with students. The student who is used to rote memorisation may well feel uncomfortable with inquiry-based learning.

As learners straddle two (or more) cultures, they need to interpret information in light of differing perspectives, and negotiate the relevant application of such information to their daily life. Particularly if the school ethos contradicts familial values, learners might artificially separate those two worlds, try to integrate the two, or reject one set of values. Instructors should take care to respect each student's cultural stance while noting the importance of learning about the social climate to be experienced as a potential employee. Furthermore, teacher-librarians would do well to contextualise content in terms of students' local reality or at least build on those realities as students need to assimilate new cultural understandings (McMahon \& Bruce, 2002).

\section{Solutions to language problems}

International students may have taken English courses, but that instruction is typically provided by teachers whose primary language is not English. British English (with a British accent) is more likely to be taught than American English, which can also impact the meaning of common terms, such as "bonnet" for car hood. Additionally, the English taught is unlikely to address technical educational vocabulary. On the other hand, as more content is being created in non-English speaking cultures, teacher-librarians may encounter more difficulties in evaluating the content's quality.

The following specific tips, largely from Sarkodie-Manash (2000), apply across the board in instruction across cultures.

- Make the structure of the class explicit.

- In all communication, use plain English and short sentences, and avoid idioms. Rephrase and simplify statements. Define new terms. Use meaningful gestures.

- If using audio files or online speech, speak clearly and slowly without accent.

- Make documents comprehensive.

- Use repetition, paraphrasing and summaries.

- Focus attention on essential vocabulary needed for the specific training or profession. Provide bilingual glossaries and visual references.

- Use visual aids and graphic organisers to help learners understand content organisation and relationships.

- Include frequent comprehension checks and clarification questions.

- If you can't understand a student, don't pretend to.

- If possible, instruct the learner's primary language (unless learners represent several native languages). Pair students linguistically. Consider providing resources in primary languages. Check the readability of written sources, and locate materials that include visual or aural cues. It should be noted that some images may be unrecognisable, demeaning, or have different meanings to difference cultures.

Technology-based instruction can ameliorate language problems significantly. E-learning tends to be textbased (with some visual support), which enables learners to consult dictionaries and peers to understand concepts. Additionally, asynchronous discussion enables learners to take their time crafting their responses in their primary language and then translating their words with less time stress. The anonymity of online communication can also make females from masculine-dominated cultures feel more comfortable voicing their opinion.

\section{E-teaching factors}

(C) 2010 IASL, SLAQ and therein by the authors. Diversity Challenge Resilience: School Libraries in Action Proceedings of the $12^{\text {th }}$ Biennial School Library Association of Queensland, the $39^{\text {th }}$ International Association of School Librarianship Annual Conference incorporating the $14^{\text {th }}$ International Forum on Research in School Librarianship, Brisbane QLD Australia, 27 September - 1 October 2010 . 
Probably the two greatest changes in culture-sensitive learning arise from learner characteristics and technology. As technology permeates the global society, people come into contact with other cultures more frequently and deeply. In some cases, those interactions may be characterised as clashes. Misunderstandings occur because of tacit assumptions and cultural perceptions. Thus, the need for understanding different cultures is more important than ever. Hofstede's 1980 model of cultural differences can aid teacher-librarians in creating culturally-sensitive online learning environments. Domer and Gorman (2006) offer several useful suggestions, which largely apply to all types of learning settings.

\section{Student-teacher relations}

Learners from high power-distance cultures expect formal, hierarchical relationships with their teachers. To ease their stress in more egalitarian or constructivist courses, teacher-librarians can clearly and explicitly define their roles, and work with students to make clear decisions about learning expectations. Personal acknowledgment rituals and relationships can also counterbalance power distance formality (Gurubatham, 2005). They can also tell students the appropriate term of address to use (e.g. Mrs. Ramirez, Mrs. R, Paula). Traditional males may feel uncomfortable having a female teacher-librarian, although e-learning environments tend to mitigate this issue. Providing information about the teacher-librarian's expertise and status, along with testimonials from high-status males, can further elevate a female librarian's credibility. Students who are shy about asking for help should have several options available: confidential email, intermediation by a course student representative/spokesperson, peer assistance, referrals to resources such as online tutorials. Teacher-librarians can pre-emptively help this situation by frequently checking for understanding (e.g. short online quizzes and quick writes) and giving all students immediate feedback.

\section{Topics of discussion}

Teacher-librarians should be aware of possible taboo subjects. This issue might emerge in health issues where gendered practices might inhibit practice. Teacher-librarians would do well to consult their peers in relevant countries to find out ahead of time what topics might be sensitive to their learners. Accommodations for alternative topics, resources, or ways of learning should be provided so as to not disadvantage affected learners. In almost all cases, connecting course concepts with real world context and applications helps all learners, not just field dependent ones.

\section{Choice of resources}

In most cases, teacher-librarians choose the material to be covered in a lesson, or they select in collaboration with classroom teachers. That selection or filtering process may reflect cultural bias that might disadvantage some international students; specific ideas might be supported and other omitted, thus shutting down opposing viewpoints. Even a simple factor of choosing examples reflecting only urban practice might ignore the needs of students working in rural areas. At the least, teacher-librarians should enable students to choose from a wide spectrum of reading materials reflecting a variety of perspectives. It should be noted that students tend to find and understand web-based information more quickly when the content is created by designers from their own cultures (Faiola \& Matei, 2005). Alternatively, teacher-librarians should permit students to seek self-relevant sources. This latter approach might trouble classroom teachers who want to control students' reading materials, which, in itself, reflects a certain cultural value. Likewise, in some cultures, such as China, students typically read only what the instructor chooses, so self-determination of materials can be uncomfortable for them at first. Furthermore, as they seek relevant resources, many non-U.S. students have little experience using school libraries and may hesitate before asking librarians for assistance.

\section{Learner participation}

Again, clear expectations and course norms from the first contact will help reduce learner confusion and distress. If the student population includes a mix of cultures, then a corresponding combination of individual and collaborative activities would be appropriate. Likewise, a mix of cooperative and competitive activities allows learners from different backgrounds to excel at different points. Alternatively, teacher-librarians can provide students with options to do work independently or with others. To accommodate learners from collective cultures, teacher-librarians may need to initiate discussion or start groups off when introducing problem-based learning; step-by-step guidelines also facilitate field dependent learners. Web 2.0 technology should also be incorporated in order to provide learners with opportunities to interact with each other,

(C) 2010 IASL, SLAQ and therein by the authors. Diversity Challenge Resilience: School Libraries in Action Proceedings of the $12^{\text {th }}$ Biennial School Library Association of Queensland, the $39^{\text {th }}$ International Association of School Librarianship Annual Conference incorporating the $14^{\text {th }}$ International Forum on Research in School Librarianship, Brisbane QLD Australia, 27 September - 1 October 2010 . 
collaborate, and produce creative work for authentic audiences. In any case, the e-learning environment should be safe and comfortable for all learners.

\section{Learning activities}

Probably the best solution for culturally-sensitive activities is inclusive instructional design that accommodates all students. Here are some other specific suggestions.

- Some students are not used to self-directed learning. Rather than telling students the answer, teacherlibrarians can model the process required to find it.

- Students may be accustomed to rote learning facts, rather than applying skills; teacher-librarians can help students apply general principles to a variety of research situations.

- Students might not be used to critically evaluating information; teacher-librarians can provide checklists or criteria for students to use in evaluating sources.

- Many students are only interested in what is needed to pass exams (achievement orientation); teacher-librarians can emphasise the importance of knowledge and skills for lifelong success as well as immediate career advancement.

\section{Technology issues}

On one hand, technology enables learners from around the world to get information at the click of a button. On the other hand, physical and intellectual access to technology remains uneven in different countries. Some areas still lack electricity, and some nations lack a stable Internet infrastructure. While cell phones have become ubiquitous, desktops and software programs may be less common. Hardware still is too costly for many people, and educational institutions may have little equipment. Particularly with the increased use of multimedia, which drains broadband signalling power, learners in developing countries may be severely disadvantaged. Even time zone differences can be a challenge for students who have to $\log$ in at 3 am in order to participate in live chat.

Furthermore, learners reflect a vast spectrum of technological experience and expertise. Some millennials may be used to the Internet since childhood, but other peers may still have problems navigating with a mouse. Additionally, learners may have an unrealistic idea of their own technical ability; instant messaging does not constitute technological fluency. The deeper issue of evaluating online information also poses an issue, particularly for learners who are not world-savvy.

Therefore, teacher-librarians need to find out what technological access their students have at school and at home, and aim for the lowest common denominator, which might consist of a frameless set of text-based web pages that are accessible via cell phone. In a couple of cases, schools have developed partnerships so that equipment could be loaned to the other country. Application programs should be free and web-based as well, such as Google's suite. Learners should be able to get technical assistance at any time, hopefully, in a language that they can understand. Teacher-librarians should also be sure to show learners how to navigate the online training, and use the required technology tools. Additional support may be in the form of a list of online tutorials, tech buddies, local tech centre help, and alternative ways to demonstrate competence such as phoning in responses.

One interesting recent development is localisation service. Private businesses are making differentiated online documents that will be culturally acceptable at the local level in terms of language, measurement units, geographic representations, gender role, colour connotations, and so on. Even metatagging (i.e. describing an item using subject headings, labels, etc.) can be localised to facilitate culturally-defined retrieval patterns. "Intelligent" tutoring systems are also being developed to offer different content and media based on the user's demographic profile. While an attractive idea, localisation services tend to offer a boiler-plate solution. They may lack of deep domain knowledge, and they certainly do not know the learners. So, at best, this service can be used to provide a draft course look, but it needs to be customised by teacher-librarians instructing the specific learner.

\section{Assessment issues}

(C) 2010 IASL, SLAQ and therein by the authors. Diversity Challenge Resilience: School Libraries in Action Proceedings of the $12^{\text {th }}$ Biennial School Library Association of Queensland, the $39^{\text {th }}$ International Association of School Librarianship Annual Conference incorporating the $14^{\text {th }}$ International Forum on Research in School Librarianship, Brisbane QLD Australia, 27 September - 1 October 2010 . 
Culture impacts student performance when information literacy skills are required. In terms of language, even simple tasks such as following directions can disadvantage some students. Some of the measures that can be taken to mitigate cultural discrepancies include: giving shorter tests and recall items rather than tasks that require language and literacy skills (Teresi, et al., 2001), provide accurate translations in those cases where language ability is not the element being tested, provide bilingual glossaries, consider the option of having students demonstrate their skill kinaesthetically (e.g. video recording their performance or having a local expert verify their ability).

Teacher-librarians also need to make sure that the test is not culturally biased, that is, one cultural group does not outperform others systemically. Bias usually occurs when cultural knowledge is assumed (e.g., use of bidets, knowledge of July 4, eating habits). Images too may have culturally-defined meanings or connotations (for example, owls connote different attributes in different cultures). The easiest approach is to check with students via non-test activities about their understanding of textual and visual information.

The writing process is another area of possible cultural misunderstanding. While U. S. students are taught to write sequentially, often relying on an outline, other cultures prefer that writers build arguments starting with a general stance and arriving at the specific issue only at the end, and still other cultures use an argument/counter-argument structure. Therefore, teacher-librarians need to focus on the content more than the presentation, or they need to specify how a report is to be written - and provide the support needed for students to succeed in writing in a particular style. Furthermore, non-U. S. cultures sometimes have a different attitude about intellectual property. Many students are not used to crediting their sources, and do not know about citation styles. A blanket punishment for plagiarism is obstructive without explicit instruction and support to help student comply with U. S. copyright laws.

Assessment also needs to take into consideration affective elements. For instance, non-cognitive variables accounted for about a quarter of the variance in grade point averages for African Americans at predominately white universities; at black universities, non-cognitive variables accounted for about eighteen percent of grade average variation (Lockett \& Harrell, 2003). The author concluded that the relationship between students and faculty influence self-confidence and self-efficacy. Even though e-learning might mitigate such differences in perception, language use in written and oral communication may indicate a person's cultural background, and might influence some party's perceptions either of the instructor or the interaction. Zhang (2000) found that deep understanding correlated significantly with achievement (as opposed to surface reproduction of information), and therefore recommended that instructors assess accordingly.

\section{Emerging learning technologies}

With the convergence and miniaturization of technology, teacher-librarians can leverage emerging technologies engage today's students, and foster active, collaborative learning.

Podcasting and videocasting compress audio and video files for portable, flexible consumption. In a study of podcast lectures, Evans (2007) found that adult learners thought podcasts were more useful than textbooks or note-taking for reinforcing learning. English language learners find "casts especially attractive because they can review the "casts repeatedly until the information is well comprehended. Instructors are also designing learning activities that require learners to create their own "casts to share with their peers or other authentic audiences.

Mobile learning, or m-learning uses handheld devices to help collection observation data and to facilitate quick in-class quizzes to check for understanding. Stripped down application programs such as word processing and concept mapping enable learners to brainstorm and journal their learning experiences easily, and then share those ideas with their peers. "Smart" phones have ratcheted up m-learning because of their many features: two-way communication, text messaging, photo capture, calendaring, calculating, Internet access, online reading, application downloading and operating options, geographic information system (GIS) or global positioning system (GPS) functions, and language support.

(C) 2010 IASL, SLAQ and therein by the authors. Diversity Challenge Resilience: School Libraries in Action Proceedings of the $12^{\text {th }}$ Biennial School Library Association of Queensland, the $39^{\text {th }}$ International Association of School Librarianship Annual Conference incorporating the $14^{\text {th }}$ International Forum on Research in School Librarianship, Brisbane QLD Australia, 27 September - 1 October 2010 . 
On a grander scale, virtual worlds enable learners to experience situated learning in three dimensions, or a facsimile thereof. Visual immersion systems, from head-mounted visual systems to 3D "caves," enable learners to experience a visual simulated environment. These systems can sense the learners' movements, and adjust the visual components accordingly.

\section{Conclusion}

The following strategies summarise the key points for teacher-librarians to follow in designing culturallysensitive learning.

- Provide clear information and expectations about learning activities, including content, technical aspects, procedures, participation, assessment, available support.

- Get to know the students, and help them learn about each other. Obtain and share demographic information. Provide opportunities for students to share their perspectives and experiences, thus enriching curriculum content.

- Create a positive learning climate. Make learning safe and comfortable so that students who are not used to voicing opinions or do not want to take intellectual risks will be supported in their efforts.

- Structure learning for meaning. Bring in cultural differences rather than masking them. Help students to connect training content to their own environments.

- Provide access to resources, and give students choices about the types of resources to use. Offer instruction or other kinds of support if students are not used to locating resources independently.

- Provide support and scaffolding for students as needed: online tutorials, local expertise, peer assistants, translation tools, technical help, time management, etc.

- Give students time to process and evaluate information. Foster critical thinking by modelling analytical information processing.

- Help students clarify and justify their understanding. Encourage study groups and study buddies as a way to refine their knowledge.

- Give timely and specific feedback throughout instruction.

- Help students self-monitor and express their learning. Give them opportunities to demonstrate competencies in several ways: written, visual, orally.

Three key learnings:

- Teacher-librarians and their students need to become culturally competent: open to learning about other cultures and sharing one's own culture, able to change personal perspectives, and able to communicate effectively across cultures.

- Teacher-librarians need to consider the following cultural factors when designing instruction regardless of delivery mode: teacher-student relations, topics of discussion, choice of resources, learner participation, learning activities, technology, and assessment.

- E-learning can provide greater cross-cultural access, but is impacted by physical and intellectual access to technology as well as cultural norms relative to e-learning.

\section{References}

Biggs, J. (1978). Individual and group differences in study processes. British Journal of Educational Psychology, 48, 266-279.

Biggs, J., Kember, D., \& Leung, D. (2001). The revised 2-factor study process questionnaire R-SP2-2F. British Journal of Educational Research, 71,133-149.

Chen, S., \& Macredie, R. (2002). Cognitive styles and hypermedia navigation: Development of a learning model. Journal of the American Society for Information Science and Technology, 53(1), 3-15.

Domer, D., \& Gorman, G. (2006). Information literacy education in Asian developing countries: Cultural factors affecting curriculum development and programme delivery. IFLA Journal, 32(4), 281-293.

C) 2010 IASL, SLAQ and therein by the authors. Diversity Challenge Resilience: School Libraries in Action Proceedings of the $12^{\text {th }}$ Biennial School Library Association of Queensland, the $39^{\text {th }}$ International Association of School Librarianship Annual Conference incorporating the $14^{\text {th }}$ International Forum on Research in School Librarianship, Brisbane QLD Australia, 27 September - 1 October 2010 . 
Evans, C. (2007). The effectiveness of m-learning in the form of podcast revision lecturers in higher education. Computers \& Education, 50, 491-498.

Faiola, A., \& Fatei, S. (2005). Cultural cognitive style and web design. Journal of Computer-Mediated Communication, 11(1). Retrieved February 13, 2010, from http://jcmc.indiana.edu/vol11/faiola.html

Gurubatham, M. (2005). Cognition, culture and effective e-praxis guiding principles. In P. Nicholson, et al. (Eds.), E-training practices for professional organizations (pp. 121-128). Boston: Kluwer Academic Publishers.

Hofstede, J. (1980). Culture's consequences: International differences in work-related values. Newbury Park, CA: Sage Publications.

Liaw, S. (2006). E-learning and the development of intercultural competence. Language Learning and Technology, 10(3), 49-64.

Lockett, C., \& Harrell, J. (2003). Racial identity, self-esteem, and academic achievement. Journal of Black Psychology, 29(3), 325-336.

Lopez-Valadez, J., Friedenberg, J., Lucas, N. Kremer, N., \& Reed, T. (1985). Immigrant workers and the American workplace: The role of voc ed. ERIC digest. Columbus, OH: ERIC Clearinghouse on Adult, Career, and Vocational Education. ED 260304.

McMahon, C., \& Bruce, C. (2002). Information literacy needs of local staff in cross-cultural development projects. Journal of International Development, 14(1), 113-137.

Sarkodie-Manash, K. (Ed.). (2000). Reference services for the adult learner. New York: Haworth Press.

Teresi, J., Holmes, D., Ramirez, M., Gurland, B., \& Lantiqua, R. (2001). Performance of cognitive tests among different racial/ethnic and education groups: Findings of differential item functioning and possible item bias. Journal of Mental Health \& Aging, 7(1), 79-89.

Zhang, Li-Fang. (2000). University students' learning approaches in three cultures. Journal of Psychology, 134(1), 37-56.

\section{Statement of Originality}

This statement certifies that the paper above is based upon original research undertaken by the author and that the paper was conceived and written by the author(s) alone and has not been published elsewhere. All information and ideas from others is referenced. 